\title{
Treatments for Improving Seed Germination in Eggplant and Related Species
}

\author{
C. Gisbert, J. Prohens and F. Nuez \\ Instituto de Conservación y Mejora de la Agrodiversidad Valenciana \\ Universidad Politécnica de Valencia \\ Camino de Vera 14, 46022 Valencia \\ Spain
}

Keywords: BAP, dormancy, Fluridone, gibberellins, Solanum

\section{Abstract}

Orthodox seeds may present differences in germination due to several reasons. Poor seed germination limits the use of different species for culture or plant breeding. In this work, we tested treatments for improving germination in two cultivars of common eggplant (Solanum melongena) and in six accessions of the related species $S$. macrocarpon, $S$. aethiopicum, and $S$. incanum. With the exception of $S$. incanum MM557, which did not germinate, seeds of the other accessions directly had lower final germination percentages when sown in Petri dishes with deep filter paper than those that were pretreated by surface sterilization and sown in nutrient medium; a further increase in the final germination percentages was achieved by addition of $1 \mathrm{mg} \mathrm{L}^{-1}$ $\mathrm{GA}_{3}$ to the medium. The $\mathrm{GA}_{3}$-pretreatment not only increased the final germination percentages but promoted germination also by reducing germination time. Other treatments included stratification of $S$. macrocarpon and $S$. aethiopicum seeds at $4^{\circ} \mathrm{C}$ for 15 or 30 days, as well as addition of $1 \mathrm{mg} \mathrm{L}^{-1}$ of TDZ and BAP for the BBS-168 accession, but this did not improve germination. The addition of $0.3 \mathrm{mg} \mathrm{L}^{-1}$ fluridone, an inhibitor of carotenoid biosynthesis, that is known to prevent $A B A$ biosynthesis, increased the final germination percentages of $S$. melongena, $S$. aethiopicum and $S$. macrocarpon to a similar degree as $\mathrm{GA}_{3}$. Seeds of $S$. incanum MM-557 did not respond to this treatment but the hybrid derived from this $S$. incanum accession with eggplant accession ANS-26 showed high germination percentages (70\%, 13 days after sowing) in NM medium with $\mathrm{GA}_{3}$, fluridone or both components. These results show that seed treatments can contribute to improving germination of Solanum accessions with low germination.

\section{INTRODUCTION}

Vegetable crops with orthodox seeds may present differences in germination due to possible dormancy, loss of viability during the conservation conditions, genetic differences among the materials, or aging. Seed dormancy is a condition of plant seeds that prevents germinating under optimal environmental conditions. Dormancy and germination are determined by the co-action of the growth potential of the embryo and the restraints imposed by the tissues surrounding it. In nature, dormancy is a mechanism that allows a number of species to survive in particular environments and regulates the time and place of germination to be most favorable for survival.

When seeds ripen they may be dormant (primary dormancy) or not dormant, that is, they germinate readily when given the proper environmental conditions of water, temperature, and/or other factors. However, seeds that do not have primary dormancy often acquire secondary dormancy as they dry.

There are three major mechanisms for imposing dormancy: (1) seed coverings that restrict water uptake, embryo expansion, gas permeability, leaching of inhibitors; (2) chemical inhibitors including several growth regulators and (3) morphological aspects such as small or undeveloped embryos. There is considerable evidence that the plant hormones abcisic acid (ABA) and gibberellins (GAs) are involved in the dormancy process. Whereas $A B A$ is involved in regulating the onset of dormancy and in maintaining the dormant state (Bewley, 1997), GAs appear not to be involved in the control of 
dormancy per se but rather are important in the promotion and maintenance of germination. An integrated view of seed dormancy and the control of germination can be found in Finch-Savage and Leubner-Metzger (2006).

Poor seed germination rate limits the use of different species for culture or plant breeding, and different treatments such us scarification, stratification and addition of different chemical substances are commonly used to promote germination in several species (Yoshioka et al., 1998; Bone, 2003; Brady and McCourt, 2003). Also dormancy mechanisms have been eliminated of some cultivated seed by selection and breeding.

In the genus Solanum, dormancy and low germination rates have been described in different species (Adebola and Afolayan, 2006; Taab and Andersson, 2009) including some accessions of Solanum melongena and related species (Joshua, 1978; Ibrahim et al., 2001; Demir et al., 2005). Thus, seeds of a number of locally cultivated Solanum species are known to emerge slowly, and about 30 days could be needed to attain germination with percentage rates between 15 and $50 \%$ in $S$. incanum, S. torvum, S. integrifolium, $S$. surattense, $S$. khasianum, $S$. sanitwongsei and hybrids of $S$. melongena $\times$ S. ingrifolium (Ibrahim et al., 2001). Scarce germination and low uniformity in percentage rates has been also described in S. incanum by Joshua (1978).

In this work we have studied seed germination and also applied several treatments for improving germination in eggplant and the related species $S$. aethiopicum, $S$. incanum and $S$. macrocarpon. These species are interesting in breeding as they display a wide variability (Daunay, 2008). Also, some accessions of these species showed resistance to several soil-borne pathogens and/or tolerance to drought (Gisbert et al., 2006; Lester et al., 1986), making them potentially useful rootstocks for common eggplant or other compatible crop species (Porcelli et al., 1990). Study and promotion of germination in these accessions is interesting for their use for breeding purposes and their potential use as rootstocks. Germination studies are also interesting for conservation and use of germplasm resources.

\section{MATERIALS AND METHODS}

Two accessions of the Solanum species $S$. aethiopicum (BBS-107, BBS-116), S. macrocarpon (BBS-117, BBS-168) and $S$. incanum (MM-557, MM-677); two $S$. melongena cultivars, Black Beauty (BB) and LF3 and the experimental hybrid S. incanum $\mathrm{x} S$. melongena (MM-557 x ANS-26) were used in our experiments. All the seeds were maintained in dry storage for two years.

In a first experiment, seed germination rates were compared among the different Solanum accessions sown directly in Petri dishes $(90 \times 25 \mathrm{~mm})$ with humid filter paper (HFP) or surface sterilized and shown in similar Petri dishes that also contained $40 \mathrm{ml}$ of sterile nutrient medium (NM) alone or with $1 \mathrm{mg} \mathrm{L}^{-1}$ of $\mathrm{GA}_{3}\left(\mathrm{NM} \mathrm{GA}_{3}\right)$. Seeds were surface-sterilized by inmersion for $10 \mathrm{~min}$ in a solution of $25 \%$ commercial bleach as described in Gisbert et al. (2006). The NM composition was: Murashige and Skoog (1962) salts including vitamins, $2 \%$ sucrose and $0.6 \%$ plant agar. The $\mathrm{pH}$ of the medium was adjusted to 5.8 with $\mathrm{KOH}$ before autoclaving at $121^{\circ} \mathrm{C}$ for $20 \mathrm{~min}$. $\mathrm{GA}_{3}$ was added to sterilized medium after filtration with sterile filters $(200 \mu \mathrm{m})$.

In a second experiment, seeds of $S$. incanum and $S$. macrocarpon accessions were stratified at $4^{\circ} \mathrm{C}$ for 15 and 30 days and then sown in Petri dishes with NM and NM with $\mathrm{GA}_{3}$.

In a third experiment, surface sterilized seeds of $S$. aethiopicum BBS-107, S. macrocarpon (BBS-168 and BBS-117), S. incanum (MM-557 and MM-667), the experimental hybrid MM-557 x ANS-26 and S. melongena LF3 were sown in NM and in NM supplemented with $1 \mathrm{mg} \mathrm{L}^{-1} \mathrm{GA}_{3}\left(\mathrm{GA}_{3}\right), 0.3 \mathrm{mg} \mathrm{L}^{-1}$ Fluridone $(\mathrm{F})$ or both $\left(\mathrm{F}+\mathrm{GA}_{3}\right)$. All these components were additioned previous sterilization by filtration to sterilized NM medium. Seeds of BBS-168 were also sown in NM supplemented with $2 \mathrm{mg} \mathrm{L}^{-1} \mathrm{GA}_{3}, 1$ $\mathrm{mg} \mathrm{L}^{-1}$ thidiazuron (TDZ) and $1 \mathrm{mg} \mathrm{L}^{-1}$ 6-bencylaminopurine (BAP).

In all these assays, 20 seeds per accession distributed in two Petri dishes were sown per treatment and maintained in a growth chamber at $25 \pm 2^{\circ} \mathrm{C}$ under a $16 \mathrm{~h}$ photoperiod with cool white light provided by fluorescent lamps $\left(90 \mu \mathrm{mol} \mathrm{m}^{-2} \mathrm{~s}^{-1}\right)$. 


\section{RESULTS}

A great variability for germination capacity in the different accessions of $S$. melongena and the related species assayed has been observed (Table 1). S. melongena and $S$ aethiopicum accessions had better germination rates than $S$ macrocarpon and $S$. incanum species, which had low or no germination. Thus, percentages of germination at $20 \mathrm{~d}$ after sowing in Petri dishes in the common germination treatment (HFP) ranged from $0 \%$ in $S$. macrocarpon BBS-117 and $S$. incanum MM-557 to $60 \%$ in $S$. melongena BB. Sterilized seeds sown on plates with NM had higher germination rates than those sown in HFP in all accessions with germinated seeds (Table 1). Addition of GA 3 to $\mathrm{NM}$ increased the germination rate in particular in $S$. macrocarpon BBS-168. Global mean percentages for HFP, NM and NM with $\mathrm{GA}_{3}$ were $23.84,55.70$ and $70.38 \%$, respectively. The addition of $\mathrm{GA}_{3}$ to $\mathrm{NM}$ medium also reduced mean germination time. Thus, in this experiment radicles and hypocotyls could be observed emerging $7 \mathrm{~d}$ post-sowing from some $S$. melongena and $S$, aethiopicum seeds in NM plus GA3. No seed of these accessions had germinated at this time ( $7 \mathrm{~d}$ post-sowing) in NM plates. A similar effect was observed in $S$. macrocarpon $\mathrm{BBS}-168$, with $50 \%$ of seeds germinated in $\mathrm{GA}_{3}$ containing medium and no germination in NM $9 \mathrm{~d}$ after sowing (Fig. 1). Stratification of $S$. incanum and $S$. macrocarpon seeds at $4^{\circ} \mathrm{C}$ for 15 and $30 \mathrm{~d}$ did not improve germination rates, which were similar to those obtained in the first experiment.

The use of Fluridone, an inhibitor of carotenoid biosynthesis that is known to prevent ABA biosynthesis, was tested in a third experiment. Germination rates were compared in plates with NM plus F, NM, NM supplemented with $\mathrm{GA}_{3}$ and NM with both $\mathrm{F}$ and $\mathrm{GA}_{3}$. Results $13 \mathrm{~d}$ after sowing were shown in Figure 2 . All components added to NM promoted germination in all accessions tested with the exception of $S$. incanum MM557 that did not germinate, as occurred in the previous assay. In general, the addition of $F$ had a similar effect to that produced by GA3. A slight synergistic effect of both added components was observed only in plates of S. macrocarpon BBS-117 and S. melongena LF3 (Fig. 2). The experimental hybrid MM-557 x ANS-26, derived from the MM-557 accession of $S$. incanum and the ANS-26 S. melongena accession, showed good germination rates (in average $70 \%$ ) in NM medium supplemented with $\mathrm{GA}_{3}, \mathrm{~F}$ or both (Fig. 2 ).

Seeds of BBS-168 sown in NM supplemented with $1 \mathrm{mg} \mathrm{L}^{-1}$ of TDZ and BAP, and with $\mathrm{GA}_{3}$ at $2 \mathrm{mg} \mathrm{L}^{-1}$ had germination rates of 30,25 and $60 \%$, respectively. Thus, TDZ and BAP did not increase germination in this accession, which had $35 \%$ of germination in NM. The addition of $2 \mathrm{mg} \mathrm{L} \mathrm{L}^{-1}$ of $\mathrm{GA}_{3}$ had similar effect than $1 \mathrm{mg} \mathrm{L}^{-1} \mathrm{GA}_{3}$. Some plantlets from plates with BAP showed swelled radicles and hypocotyls. Also in TDZ some seeds gave abnormal plantlets.

\section{DISCUSSION}

A great variability for germination capacity in the different accessions of $S$. melongena and the related species $S$. aethiopicum, $S$. incanum and $S$. macrocarpon has been observed in these assays. In general, germination in $S$. melongena and $S$. aethiopicum is better than in $S$. macrocarpon and $S$. incanum, which had low or no germination. Dormancy, loss of viability during extraction or conservation conditions, genetic differences among the materials, aging or combination of these factors could explain these differences.

In order to increase germination rates several treatments have been applied. Sterilization and germination in NM resulted in higher germination rates than in HFP, the most common germination procedure in our laboratory to test seed germination. This promotion of germination could be the result of scarification and/or hydration suffered in the sterilization procedure of seeds, and/or of a better nutrient uptake. Soaking seeds in water was found to increase the germination rate in Solanum aculastrum (Adebola and Afolayan, 2006). Sterilization of seeds and culture on NM medium in vitro is laborious but permits to test the effect of several compounds, homogeneously added, and to follow the germination process in sterile conditions during a long period if necessary. In this work, several compounds were added after filtration. 
The addition of $\mathrm{GA}_{3}$ to culture medium has significantly enhanced germination in $S$. macrocarpon BBS-168 and, in general, in the rest of the treated accessions. There is considerable evidence that GAs are important in the promotion and maintenance of germination, and the application of $\mathrm{GA}_{3}$ was effective in breaking dormancy in different plants including trees as Myrica rubra (Chen et al., 2008); weeds as leafy spurge (Foley and $\mathrm{Chao}_{2} 2008$ ), etc. In several species of Solamum, $\mathrm{GA}_{3}$ has been used to promote germination with different results. Thus, Joshua et al. (1978) reported a higher efficiency of the treatment with $\mathrm{GA}_{3}$ (GA, 500 ppm for 6 day) for promoting germination in $S$. incanum compared with decoated seeds, and the use of alternating temperatures $\left(10 / 25^{\circ} \mathrm{C}\right)$. However, only a germination increase among $10-34 \%$ was produced in 3 of the 8 Solanum species treated with a $\mathrm{GA}_{3}$ solution $\left(100 \mathrm{mg} \mathrm{L}^{-1}\right.$ in water for $24 \mathrm{~h}$ ) by Ibrahim et al. (2001). We have also observed that seeds sown in $\mathrm{GA}_{3}$ containing medium germinated before than those in NM. This effect has been observed in all $S$. melongena and $S$. aethiopicum accessions tested, and also in $S$. macrocarpon BBS-168. In some species like Santalum album (Nikam and Barmukh, 2009) a reduction in mean germination time after $\mathrm{GA}_{3}$ application has been reported.

Other treatments applied in order to promote germination of $S$. macrocarpon and $S$ incamum seeds were stratification at $4^{\circ} \mathrm{C}$ and addition of Fluridone to NM medium. These treatments were used to promote seed germination in some species. For instance, Fluridone has restored the seed germination of some Lactuca sativa L. cultivars (Yoshioka et al., 1998). In this work, the temperature or time applied in the stratification treatment has not modified germination rates, but the addition of $0.3 \mathrm{mg} \mathrm{L}^{-1} \mathrm{~F}$ increased germination in both accessions of $S$. macrocarpon, in the hybrid from $S$. incanum $x$. melongena and in the accessions of $S$. aethiopicum and $S$. melongena included in this experiment. This result indicates that, probably, ABA is limiting germination in these Solanum seeds. Comparation of germination rates in plates with $\mathrm{GA}_{3}, \mathrm{~F}$ or both indicate that $\mathrm{F}$ promotes germination with a similar range to that of $\mathrm{GA}_{3}$. A slight synergistic effect F- GA $A_{3}$ was observed in plates of S. macrocarpon BBS-117 and S. melongena LF3.

BAP has been used in in vitro embryo germination in aged almond (San and Yildirim, 2009) and also enhanced germination in Sorghum bicolor (Tiryaki and Buyukcingil, 2009). In our work, the addition of $1 \mathrm{mg} \mathrm{L}^{-1}$ of BAP or TDZ to NM medium had no possitive effect in germination of $S$. macrocarpon BBS-168 seeds.

None of assayed treatments has promoted $S$ incanum MM-557 germination, which could have lost viability or may suffer seasonal changes in seed dormancy as has been described in Solanum nigrum and Solanum physalifolium by Taab and Andersson (2009), who explained the late emergence of the species by a short-lived dormancy induction.

In conclusion, dormancy and germination are complex traits, and under similar storage conditions great differences for germination rate have been observed in the assayed accessions of $S$. melongena and some related species. Of the assayed treatments, sterilization of seeds and sowing in NM sterile medium with $\mathrm{GA}_{3}$, Fluridone or both are the best for promoting germination in most of the assayed accessions.

\section{ACKNOWLEDGEMENTS}

This contribution was financed by the "Ministerio de Ciencia e Innovación" grants AGL2006-04878/AGR, AGL2009-07257, and RF2008-00008-00-00.

\section{Literature Cited}

Adebola, P.O. and Afolayan, A.J. 2006. Germination responses of Solanum aculeastrum, a medicinal species of the Eastern Cape, South Africa. Seed Sci. Technol. 34:735-740.

Bewley, J.D. 1997. Seed germination and dormancy. Plant Cell. 9:1055-1066.

Bone, M. 2003. Germination of woody legumes from green seed. Proc. Int. Plant Prop. Soc. $53: 372$.

Brady, S.M. and McCourt, P. 2003. Hormone cross-talk in seed dormancy, J. Plant Growth Reg. 22:25-31. 
Chen, S.Y., Kuo, S.R. and Chien, C.T. 2008. Roles of gibberellins and abcisic acid in dormancy and germination of red bayberry (Myrica rubra) seeds. Tree Physiol. 28: 1431-1439.

Daunay, M.C. 2008. Eggplant. p. 163-220. In. J. Prohens and F. Nuez (eds.), Handbook of plant breeding: Vegetables II. Springer, New York, USA.

Demir, I., Ermis, S., Okçu, G. and Matthews, S. 2005. Vigour tests for predicting seedling emergence of aubergine (Solanum melongena L.) seed lots. Seed Sci. Technol. 2:481484.

Finch-Savage, W.E. and Leubner-Metzger, G. 2006. Seed dormancy and the control of germination. New Phytol. 171:501-553.

Foley, M.E. and Chao, W.S. 2008. Growth regulators and chemicals stimulate germination of leafy spurge (Euphorbia esula) seeds. Weed Sci. 56:516-522.

Gisbert, C., Prohens, J. and Nuez, F. 2006. Efficient regeneration in two potential new crops for subtropical climates, the scarlet (Solanum aethiopicum) and gboma ( $S$. macrocarpon) eggplants. New Zeal. J. Crop Hort. Sci. 34:55-62.

Ibrahim, M., Munira, M.K., Kabir, MS., Islam, A.K.M.S. and Miah, M.M.U. 2001. Seed germination and graft compatibility of wild Solanum as rootstock of tomato. Online J. Biol. Sci, 1:701-703.

Joshua, A. 1978. Seed germination of Solanum incanum: an example of germination problems of tropical vegetable crops. Acta Hort. 83:155-162.

Nikam, T.D, and Barmukh, R.B. 2009. $\mathrm{GA}_{3}$ enhances in vitro seed germination in Santalum album. Seed Sci. Technol. 37:276-280.

Lester, R.N., Hakiza, J.J.H., Stavropoulos, N. and Teixiera, M.M. 1986. Variation patterns in the African Scarlet Eggplant, Solanum aethiopicum L. p.283-307. In: B.T. Styles (ed.), Intraspecific classification of wild and cultivated plants. Clarendon Press, Oxford, UK.

Porcelli, S., Morra, L., del Piano, L. and D'Amore, R. 1990. Osservazione sull'affinitá ed comportamento vegeto-produttivo di innesti tra melanzana ed altre Solanaceae. Colture Protette 19:75-80.

San, B. and Yildirim, A.N. 2009. Seed and in vitro embryo germination in aged almond. Seed Sci. Technol. 37:365-371.

Taab, A and Andersson, L. 2009. Seasonal changes in seed dormancy of Solanum nigrum and Solanum physalifolium. Weed Res. 49:90-97.

Tiryaki, I. and Buyukcingil, Y. 2009. Seed priming combined with plant hormones: influence on germination and seedling emergence of sorghum at low temperature. Seed Sci. Technol. 37:303-315.

Yoshioka, T., Endo, T. and Satoh, S. 1998. Restoration of seed germination at supraoptimal temperatures by fluridone, an inhibitor of abscisic acid biosynthesis. Plant Cell Physiol. 39:307-312. 


\section{Tables}

Table 1. Final germination percentages in humid filter paper (HFP), nutrient medium (NM) and $\mathrm{NM}$ with $1 \mathrm{mg} \mathrm{L}^{-1} \mathrm{GA}_{3}\left(\mathrm{NM}-\mathrm{GA}_{3}\right)$.

\begin{tabular}{lccc}
\hline & HFP & NM & NM-GA \\
\hline S. melongena BB & 60 & 95 & 100 \\
S. melongena LF3 & 40 & 85 & 90 \\
S. aethiopicum BBS-116 & 30 & 80 & 95 \\
S. aethiopicum BBS-107 & 40 & 80 & 85 \\
S. macrocarpon BBS-168 & 15 & 30 & 60 \\
S. macrocarpon BBS-117 & 0 & 0 & 2 \\
S. incanum MM-557 & 0 & 0 & 0 \\
S. incanum MM-657 & 2 & 6 & 6 \\
\hline Global mean $^{\mathrm{a}}$ & $23.84 \mathrm{c}$ & $55.70 \mathrm{~b}$ & $70.38 \mathrm{a}$ \\
\hline
\end{tabular}

${ }^{\mathrm{a}}$ Global means separated by different letters are significantly different $(\mathrm{P}<0.05)$ according to the Tukey test.

\section{Figures}

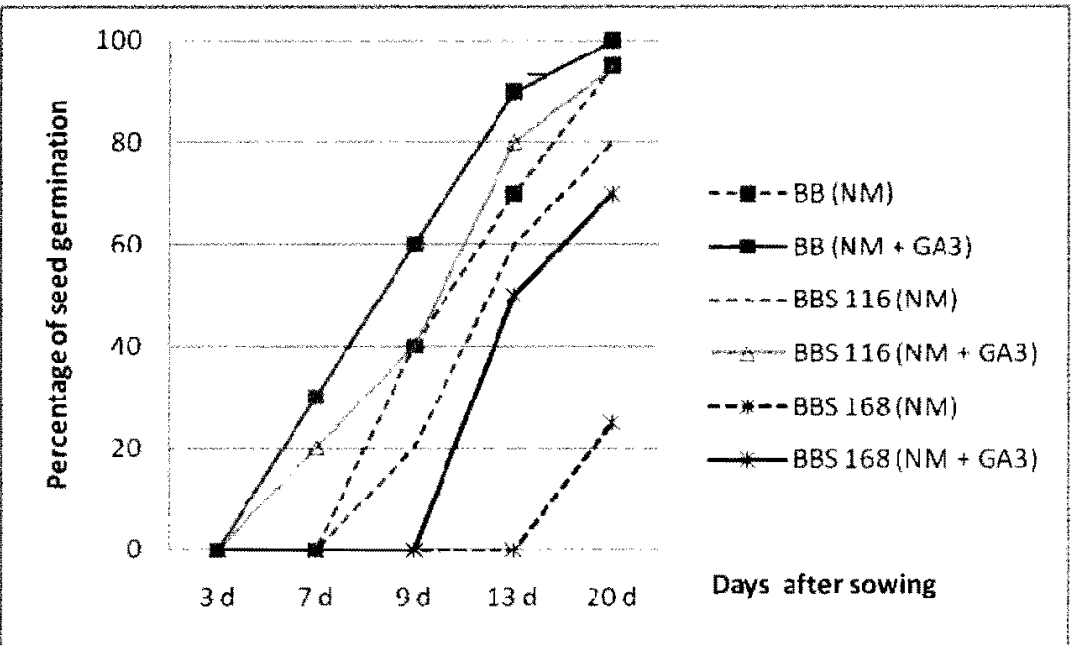

Fig. 1. Seed germination time courses of $S$. melongena (BB), S. aethiopicum (BBS 116) and $S$. macrocarpon (BBS 168) sown in Petri dishes with NM (--) and NM with $\mathrm{GA}_{3}(-)$ at $3,7,9,13$ and $20 \mathrm{~d}$ after sowing. 


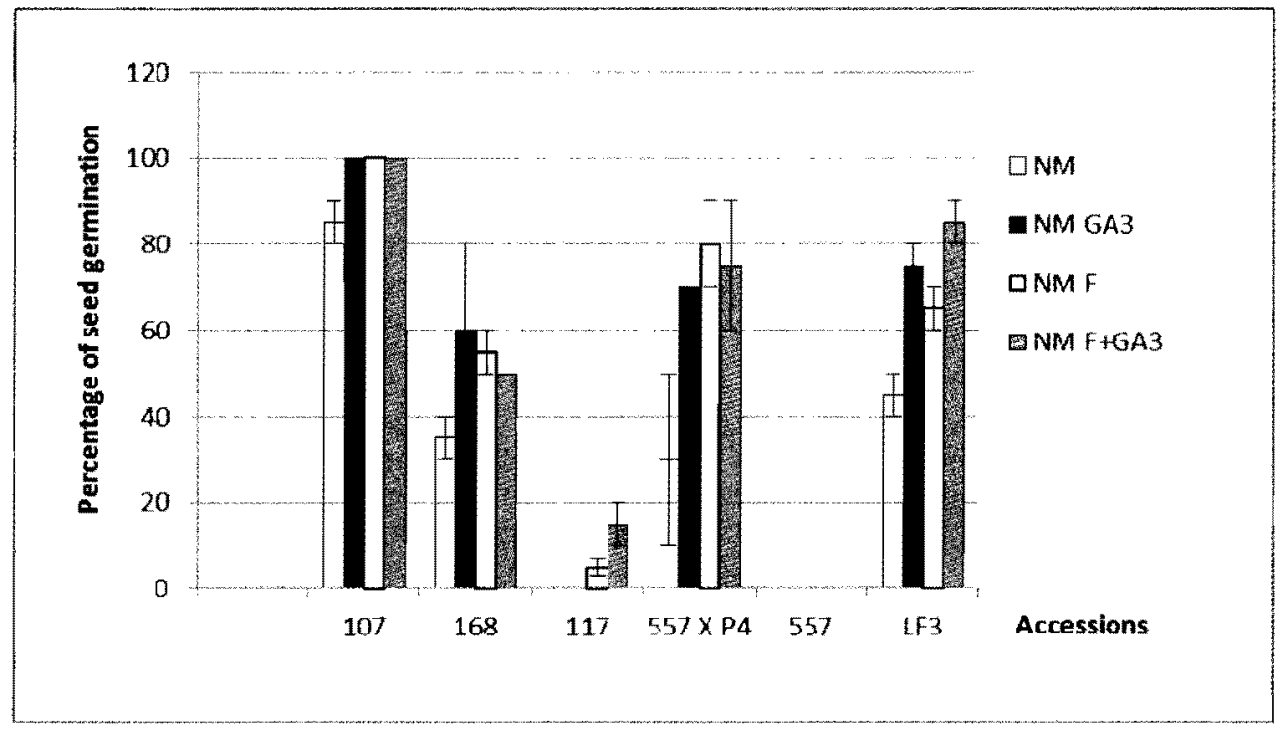

Fig. 2. Percentages of seed germination $13 \mathrm{~d}$ after sowing in NM and NM with $\mathrm{GA}_{3}$ $\left(1 \mathrm{mg} \mathrm{L}^{-T}\right), \mathrm{F}\left(0.3 \mathrm{mg} \mathrm{L}^{-1}\right)$ and $\mathrm{F}+\mathrm{GA}_{3}$. Bars represent $\pm \mathrm{SE}$. 